\title{
Estimation Of Demand For Fish In Delhi And NCR, India
}

https://doi.org/10.21272/sec.5(4).46-54.2021

\section{Ravi Shankar Kumar}

Masters Scholar, Fisheries Economics Extension and Statistics Division, ICAR-Central Institute of Fisheries Education, Mumbai, India

M. Krishnan, ORCID ID: https://orcid.org/0000-0003-0288-7162

Principal Scientist \& Head (Retired), Fisheries Economics Extension and Statistics Division, ICAR-Central Institute of Fisheries Education, Mumbai, India

\section{Praduman Kumar}

Principal Scientist \& Head (Retired), Division of Agricultural Economics, Indian Agriculture Research Institute, N. Delhi 110012, India

Badri Narayan G., ORCID ID: https://orcid.org/0000-0001-9628-8173

Senior Economist, Infinite Sum Modelling Inc, Seattle, USA

\section{Swadesh Prakash}

Principal Scientist, Fisheries Economics Extension and Statistics Division, ICAR-Central Institute of Fisheries Education, Mumbai, India

\section{Dhande Kranthi Kumar}

Masters Student, Fisheries Economics Extension and Statistics Division, ICAR-Central Institute of Fisheries Education, Mumbai, India

\begin{abstract}
Fast population growth, increase in per capita income and increase in level of awareness among the people regarding health are the main causes of increase in demand for nutritional and protein rich food. Fish is very good source of protein as well as vitamins. Fish may play a vital role to ensure the nutritional security in rural areas. Fish production and consumption has however undergone major uneven changes in the past four decades. It is found that at higher ends of the income distribution, the consumption of milk, eggs, meat, fish and processed foods have risen. Present study focuses on the demand for fish in Delhi and NCR in comparison to other items like chicken, mutton and eggs. A Three Stage Budgeting Framework of demand is used for present analysis. NSSO data of household consumption has been used for analysis. Per capita consumption of "fish", "chicken" and "mutton" in Delhi and NCR were estimated and it was found to be $4.04 \mathrm{~kg} /$ annum, 2.27 $\mathrm{kg} /$ annum and $0.81 \mathrm{~kg} /$ annum respectively. So, per capita consumption of "fish" was found to be greater than "chicken" as well as "mutton". Income elasticity of demand was estimated for each income group of population and in most of the cases demand for fish was found to be income elastic. Compensated as well as noncompensated price elasticity of demand for fish was also estimated. It was found that price elasticity of fish was almost unitary elastic whereas price elasticity of chicken" and mutton were price inelastic. Fish demand was also projected up to 2020 and it was found to be $5.11 \mathrm{~kg} / \mathrm{capita} / \mathrm{annum}$ in 2020 . With increase in income of the population as well as awareness of health benefit of fish, it is expected that fish consumption will increase at a very fast rate in future. However the presence of a large proportion of vegetarian population in Delhi and NCR is a challenging proposition for increasing of overall fish consumption of Delhi and NCR.
\end{abstract}

Key words: demand, elasticities, three stage budgeting framework, fish.

JEL Classification: D12, D16, E21, R22. 
Cite as: Ravi Shankar Kumar, M. Krishnan, Praduman Kumar, Badri Narayan G., Swadesh Prakash, Dhande Kranthi Kumar (2021). Estimation Of Demand For Fish In Delhi And NCR, India? SocioEconomic Challenges, 5(4), 46-54. https://doi.org/10.21272/sec.5(4).46-54.2021.
Received: 07.09 .2021
Accepted: 17.11 .2021
Published: 30.12 .2021

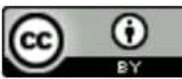

Copyright: (C) 2021 by the authors. Licensee Sumy State University, Ukraine. This article is an open access article distributed under the terms and conditions of the Creative Commons Attribution (CC BY) license (https://creativecommons.org/licenses/by/4.0/).

\section{Introduction}

Economic growth in addition to the development components and structural changes is also typically related to improvements in food supply in the country in both quantitative and qualitative terms and also a gradual reduction in food scarcities and nutritional deficiencies among the people. To promote healthy diets and life styles and reduce the global burden of the non-communicable diseases, it is necessary to adopt to ensure a balanced dietary pattern, which not only affect the physiological function of body but also has a psychological impact. Fish is relatively inexpensive, nutritious and has a wide market helping to ensure such diet. Food strategies must not merely be directed towards ensuring food security for all, but must also achieve the consumption of adequate quantities of safe and good quality food that together makes up a healthy diet ensuring food and nutritional security.

The emerging production technologies, higher economic growth, population explosion and shifts in dietary pattern are the driving force for rapid growth in the demand for food and non-food items, especially food items of animal origin (Kumar, 2005). Fish is a very important component of food items of animal origin. It is a very good source of protein. Demand for fish is increasing day by day because people are becoming more and more aware of the importance of fish as a source of nutritious food. Demand for fish varies spatially and temporally.

Fish consumption has undergone major changes in the last four decades. It is observed that apparent global per capita fish consumption has been increasing steadily, from an average consumption of $9.9 \mathrm{~kg} / \mathrm{capita} / \mathrm{annum}$ in the $1960 \mathrm{~s}$ to $11.5 \mathrm{~kg} / \mathrm{capita} / \mathrm{annum}$ in the $1970 \mathrm{~s}$. It further increased to $12.5 \mathrm{~kg} / \mathrm{capita} / \mathrm{annum}$ in the $1980 \mathrm{~s}, 14.4$ $\mathrm{kg} / \mathrm{capita} / \mathrm{annum}$ in the $1990 \mathrm{~s}$ and reached $16.4 \mathrm{~kg} / \mathrm{capita} / \mathrm{annum}$ in 2005 and $19.2 \mathrm{~kg} / \mathrm{capita} / \mathrm{annum}$ in 2012. However, it was found that increase in consumption is not uniform across regions (FAO 2014).

From nutritional point of view, it is found that fish contributes up to $180 \mathrm{kcal} /$ capita /day, but such a high levels is achieved only in a few countries where there is lack of alternative protein rich foods grown locally or where there is a strong preference for fish (Iceland, Japan) due to local availability. It is observed that fish contributes up to 50 per cent of total animal protein intake in some small island and some countries like Bangladesh, Cambodia, Equatorial Guinea, French Guiana, the Gambia, Ghana, Indonesia and Sierra Leone. The demand for fish is not only determined by income (purchasing power) of the consumers but also by their tastes and preferences. There is diversification in consumption of different non-vegetarian items across different states of India due to availability and tastes and preference.

Total per capita fish consumption of India is $9.8 \mathrm{~kg} /$ annum (NSSO, 2011). The consumption of fish has grown faster than that of any other product of animal origin. Disparities in fish consumption pattern is found to be exist widely across the income groups, location of the households (rural, urban, costal, etc.), and regions (Kumar and Dey, 2004).

Present paper has been developed to estimate the demand for fish in the state of Delhi and NCR. This study becomes important from the fact that the capital state has an enormous floating population and the socioeconomic parameters that govern the fabric of the society has displayed enormous adaptability to the ever changing situations of demand for both food and non-food items among its population (Kumar, 2016). 


\section{Methodology}

\section{The Data}

In India, The National Sample Survey Organisation (NSSO) is the only source of consumer expenditure data of different food commodities. In this study, NSSO household consumer expenditure survey data of year 2011 is used for the estimation of elasticities as well as consumption pattern of fish in Delhi and NCR. The NCR (National Capital Region) comprises Delhi and some districts of neighbour states like- Rajasthan, Haryana and Uttar Pradesh. Total NCR sample data covers 3121 households.

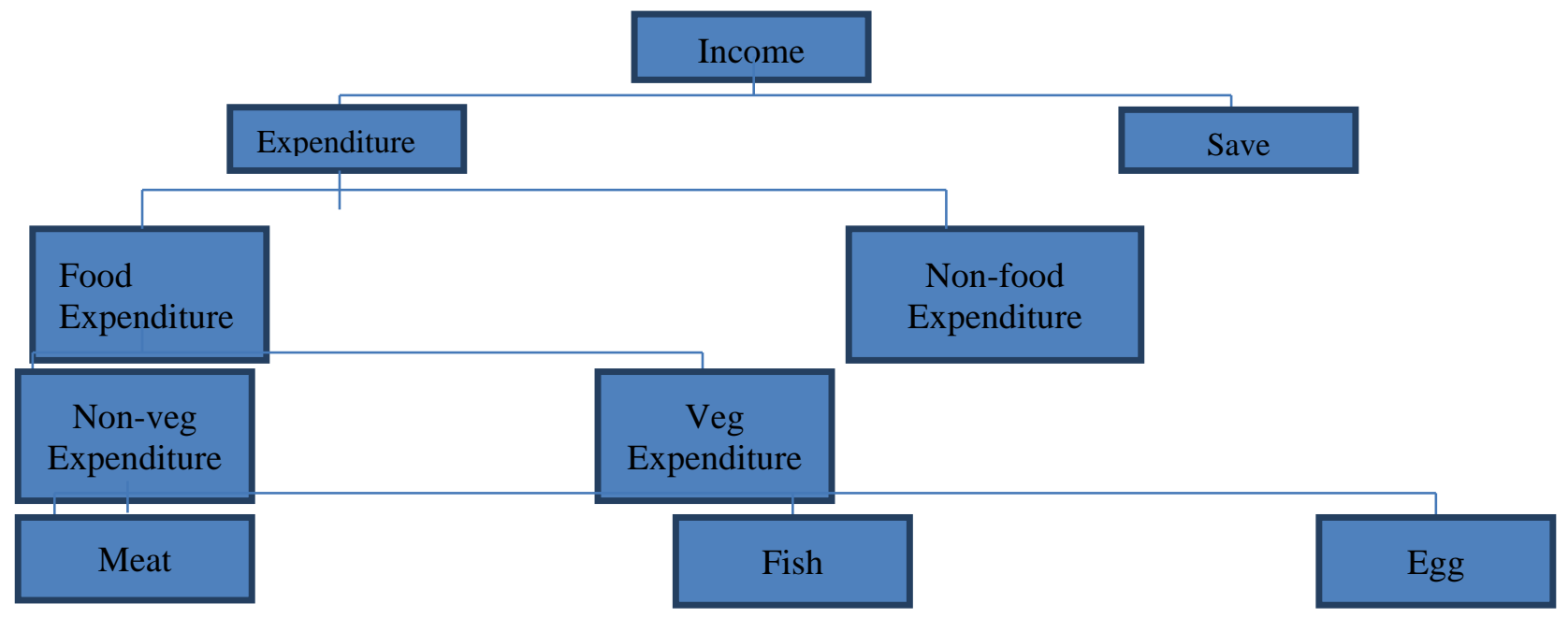

Fig. 1. Demand Model: Multistage budgeting framework (MBF)

Source: Flow chart of Multistage Budgeting Framework.

The primary goal of the study was for the estimation of demand for fish in Delhi and NCR. Systematic review of literature revealed that a multistage budgeting framework (MBF) was the best approach to study the fish consumption behaviour of the target location and for modelling the same. The MBF uses the concept of expenditure system at different level or stages (Deaton and Muellbauer (1980), Blundell et al. (1993), Kumar (2017). Defined estimation for fish in India was addressed by Kumar (2005) using the MBF. The same approach was also used by Dey (2000) in Bangladesh and Garcia et al. (2005) in Philippines for studying fish demand.

The unique advantage of the MBF technique lies in its capacity to handle simultaneous equation for empirical estimation of system demand model when faced with a wide variety of consumption goods jointly purchased by households (Blundell et al., 1993; Fan et al., 1995; Tiffin and Tiffin, 1999). It is always difficult and impractical to estimate a full demand system consisting of all consumer goods which involves a large number of own and cross elasticity parameters under constraint of limited data availability. Therefore under such circumstances the estimation procedure would involve modeling in stages. The model is then estimated sequentially in stages by incorporating expenditure on goods belonging to broad fish groups by adopting a three stage budgeting framework flexible enough to specify the fish demand system that will be species specific in the final stage. The two stage model included per capita expenditure function developed for food and for fish respectively. Later QUAIDS model is suggested which is a quadratic extension of the Deaton and Muellbauer's linear approximate AIDS model (1980) used for this study.

Consumption expenditure on food and non-food commodity is affected not only by income but by some demographic property of household. The model is used in 3 stages.

Stage 1: Equation 1 below gives the food expenditure function (F D)

$\mathrm{FD}=\mathrm{f}(\mathrm{PF}, \mathrm{PNF}, \mathrm{Y}, \mathrm{Y} 2, \mathrm{Z})$ 
$\mathrm{PF}=$ Geometric mean of food prices $=\Sigma \mathrm{Wj} \ln \mathrm{Pj}$

$\mathrm{W}_{\mathrm{j}}=$ share of $\mathrm{j}^{\text {th }}$ commodity in food expenditure

$\mathrm{P}=$ price of $\mathrm{j}^{\text {th }}$ commodity

$\mathrm{PNF}=$ price index for non-food commodity

$\mathrm{Y}=$ Income variable capturing linear expenditure

$Y^{2}=$ Income variable capturing non-linear expenditure

$\mathrm{Z}=$ Dummy variable representing demographic factors which may affect consumption such as family size, urban, rural etc.

Equation 1 assumes negligible substitution effect between food and non-food.

Income effect of changes in PNF is also taken into consideration by this proxy variable and substitution effect between food and non-food commodities which is supposed to be negligible.

The variable $\mathrm{Y}$ indicates the income capturing both linear and squared forms while $Y^{2}$ (a quadratic term) captures non-linear food consumption behavior of households.

Stage 2: In stage 2, fish expenditure (FS) specified. Fish expenditure is the function of different types of substitute foods and complimentary foods and it is defined as follows:

$\mathrm{FS}=\mathrm{f}\left(\mathrm{P}, \mathrm{FD}^{*}, \mathrm{FD}^{* 2}, \mathrm{Z}\right)$

$\mathrm{P}=$ Vector representing the prices of various food commodities

$\mathrm{FD}=$ Instrumental variable calculated in stage 1.

$\mathrm{FD}^{2}=$ Indicates the non-linear forms of FD.

Stage 3: In stage 2, QUAIDS model for specific fish type is specified. Budget share of each fish type $\left(\mathrm{W}_{\mathrm{i}}\right)$ is the function of fish prices and fish expenditure. QUAIDS model is given by following system of equation:

$W_{i}=f\left(P F, \frac{F S^{*}}{P^{*}}, \frac{F S^{* 2}}{P^{*}}, Z, I M R_{i}\right)$

$P^{*}=$ Household-specific stone's price index for fish $\left(\log P^{*}=\Sigma_{k} W_{k} \log P_{k}\right)$. This stone price is used in the model for estimation of non-linear form of the AIDS model in linear form. Although some economists like Moschini (1995), Asche and Wessels (1997) criticize the use of price index and since the felled that it may lead to introduction of measurement errors; in spite of the fact stone price is used.

The assumption in QUAIDS model is that the separability of fish is low and this assumption is necessary. This assumption describes the independence of marginal utilities derived from fish consumption from marginal utilities of other food. (Eales and Unnevehr, 1988).

The consumption of fish in some households are zero, which contribute bias in the model. So, to avoid this type of possible bias, Inverse Mill ratios (IMRs) are used (Heien and Wessells 1990). In these cases value of Wi is assumed to be zero. Tobit specification in second stage of QUAIDS model may also be used to avoid such bias.

The uncompensated price elasticities, in which both income as well as substitution effects are considered, are estimated by using the results of QUAIDS model:

$\varphi_{i j}=\left(\frac{b_{i}}{W_{i}}\right)-\left\{c_{1 i}+2 c_{2 i} \ln (F S)\right\}\left(W_{j} / W_{i}\right)-k_{i j}$

Where,

$K_{i j}$ is used for Knonecker delta; $K_{i j}$ is 1 for own price elasticity and it is zero for cross-price elasticity. 
$W_{i}$ is the Consumption share of $i^{\text {th }}$ food items and $b_{i}$ and $c_{i}$ are the parameter which is estimated by QUAIDS model.

Food expenditure elasticity of individual food items is given by following equation:

$\eta_{i}=\left(c_{1 i}+2 c_{2 i} \ln \left(\frac{F S}{W_{i}}\right)+1\right)$

Where $\eta_{i}=$ Fish expenditure elasticity.

The income elasticity for a specific food item is computed by using food expenditure elasticity $\eta^{\mathrm{FD}}$ and fish expenditure elasticity $\eta^{\mathrm{FS}}$ which is already estimated in earlier:

$\eta_{i}^{y}=\left(\eta^{F D}\right)\left(\eta^{F S}\right)\left(\eta_{i}\right)$

Where $\eta_{i}^{y}$ is income elasticity for specific food items.

The price and income elasticities are computed with the use of elasticity formula for different food items at the different level of income.

\section{Result and discussion}

Consumption (C) is the function of income (Y). Per capita income of Delhi is highest among all states of India. Delhi's per capita income is INR 0.241 million per annum. So, consumption of food and non-food items is very high in Delhi and NCR. From the table 1, it is clear that as far as per capita fish consumption is concerned, it is low because of a large proportion of vegetarian population in Delhi and NCR. It is estimated that per capita fish consumption in Delhi and NCR for fish eating households is about $4.04 \mathrm{~kg}$ which is less than per capita fish consumption in India which is $10.2 \mathrm{~kg}$ (2011).

Per capita consumption of poultry is only $2.27 /$ capita/ annum, which shows the preference of fish over poultry in Delhi and NCR. Rest of the component of MFE; contribute very less as far as consumption is concerned. Per capita consumption of mutton in Delhi and NCR is 0.81/annum whereas per capita consumption per annum of pork and beef is only 0.26 and 0.31 respectively.

Table 1. Consumption pattern of MFE for fish eating households in Delhi and NCR

\begin{tabular}{|l|c|}
\hline Items & Consumption(kg/capita/annum) \\
\hline Eggs (in number) & 46.82 \\
\hline Goat & 0.81 \\
\hline Fish & 4.04 \\
\hline Pork & 0.26 \\
\hline Poultry & 2.27 \\
\hline Beef & 0.31 \\
\hline Mfe & 10.5 \\
\hline
\end{tabular}

Source: NSSO data, 2011.

Per capita Consumption of different non-vegetarian items is found to be different at different levels of income for fish eating households of Delhi and NCR. It is observed that per capita consumption of almost all nonvegetarian items is more in upper income groups, which can be seen in table 2.

Table 2. Consumption pattern of MFE products by fish eating families across income groups in DELHI and NCR

\begin{tabular}{|l|c|c|c|c|}
\hline \multirow{2}{*}{ Items } & \multicolumn{5}{|c|}{ Consumption in kg/capita/annum } \\
\cline { 2 - 5 } & \multicolumn{4}{|c|}{ Income Group } \\
\cline { 2 - 5 } & 1 & 2 & 3 & 4 \\
\hline Fish & 0.91 & 2.12 & 2.29 & 5.16 \\
\hline Goat & 0.00 & 0.53 & 0.71 & 0.91 \\
\hline Pork & 0.00 & 0.00 & 0.00 & 0.41 \\
\hline
\end{tabular}


Table 2 (cont.). Consumption pattern of MFE products by fish eating families across income groups in DELHI and NCR

\begin{tabular}{|l|c|c|c|c|}
\hline \multirow{2}{*}{ Items } & \multicolumn{4}{|c|}{ Consumption in kg/capita/annum } \\
\cline { 2 - 5 } & \multicolumn{4}{|c|}{ Income Group } \\
\cline { 2 - 5 } & 1 & 2 & 3 & 4 \\
\hline Poultry & 0.61 & 0.53 & 1.29 & 2.95 \\
\hline Beef & 0.00 & 0.00 & 0.08 & 0.46 \\
\hline Egg (In number) & 0.00 & 15.87 & 44.25 & 52.08 \\
\hline Mfe & 1.52 & 4.13 & 7.03 & 13.01 \\
\hline
\end{tabular}

Source: Estimated from NSSO data, 2011.

Income group 1: Per capita weekly expenditure < 85 INR (1.3\$ approx.)

Income group 2: Per capita weekly expenditure in the range 85- 121 INR (1.3-1.86\$ approx.)

Income group 3: Per capita weekly expenditure in the range 122- 170 INR (1.87-2.61\$ approx.)

Income group 4: Per capita weekly expenditure >Rs 170 INR (> 2.61\$ approx.)

Share of food and non-food expenditure in total expenditure for the households of Delhi and NCR is shown in table 3, which indicates the dominance of non-food expenditure over food expenditure.

Table 3. Share of food and non-food expenditure in total expenditure for the households of Delhi and NCR

\begin{tabular}{|c|c|c|}
\hline \multirow{2}{*}{ Expenditure } & Fish eating household & Whole population \\
\cline { 2 - 3 } & Share in \% & 39.63 \\
\hline Food expenditure & 34.82 & 60.37 \\
\hline Non-food expenditure & 65.18 & 30808.83 \\
\hline Total expenditure (rupees/capita/year) & 38500.30 & \\
\hline
\end{tabular}

Source: Estimated from NSSO data, 2011.

\section{Income elasticity}

Income elasticity of different non vegetarian items for different income groups of Delhi and NCR is shown in the table: 9. multistage budgeting framework model has been applied for the estimation of demand for different non-vegetarian food items. It can be seen from the table that the elasticity has been estimated in 3 stages (E1, E2, E3). In $1^{\text {st }}$ stage of estimation of elasticity (E1), the response of demand towards food items with respect to changes in income has been estimated. In E2 the response of change in demand in MFE with respect to changes in income has been captured. In the $3^{\text {rd }}$ stage of elasticity, the response of demand for fish with changes in income has been estimated. In $1^{\text {st }}$ stage of MBF, the elasticity E1 for food is found to be 0.6 , which indicates that food items are normal goods for population of Delhi and NCR. In $2^{\text {nd }}$ stage of multistage budgeting framework, elasticity for non-vegetarian items (MFE), E2 was found to be 0.58 , which indicated that these items were also a normal good but they were found to be more income elastic than food items for the population of Delhi and NCR. In $3^{\text {rd }}$ stage of MBF, elasticity for different non-vegetarian items, E3 was found to be 0.92, $0.96,-0.87,0.95,1.43$ and 0.42 for fish, goat, pork, poultry, egg and beef respectively. So it was clear that in $3^{\text {rd }}$ step, poultry and mutton and egg were more income elastic than fish. When overall income elasticity was considered, the income elasticity of demand for fish (0.32), mutton (0.33), pork (-0.3), Chicken (0.33), eggs (0.49) was found to be positive and less than one, which indicated that these non-vegetarian items were considered as the normal goods among the households of Delhi and NCR whereas income elasticity of demand for pork $(-0.30)$ and beef $(-0.14)$ were found to be negative which indicated that pork was not preferred item among the households of Delhi and NCR. Income elasticity of demand of fish was less than the income elasticity of demand for mutton, chicken and eggs which indicated that demand for mutton, chicken and eggs was found to be fluctuating more with changes in price than fish among households of Delhi and NCR. If, the income elasticity of demand was more than 1 then these goods are called superior goods. So, none of the above non vegetarian items were found to be superior good for the population of Delhi and NCR. 
Table 4. Income elasticity of demand for different food items

\begin{tabular}{|l|c|c|c|c|}
\hline Food items & E1 & E2 & E3 & E \\
\hline Fish & 0.6 & 0.58 & 0.92 & 0.32 \\
\hline Goat & 0.6 & 0.58 & 0.96 & 0.33 \\
\hline Pork & 0.6 & 0.58 & -0.87 & -0.3 \\
\hline Poultry & 0.6 & 0.58 & 0.95 & 0.33 \\
\hline Eggs & 0.6 & 0.58 & 1.43 & 0.49 \\
\hline Beef & 0.6 & 0.58 & -0.42 & -0.14 \\
\hline
\end{tabular}

Source: Estimated values/ NSSO data, 2011.

\section{Price elasticity}

Change in demand with change in price is termed as price elasticity. There are two approaches to calculate price elasticity of demand, The Hicksian demand function (Hicks, 1969, 1985) and Marshallian demand function (Marshall, 1890, 1892). The Hicksian demand function gives compensated price elasticity of demand and Marshallian demand function gives uncompensated price elasticity of demand. The difference between the Hicksian demand function and Marshallian demand function is that in the Hicksian system, the consumer continues to be at the same utility level when there is a change in demand with an increase in price. Therefore it assumed that consumer gets compensated for the price increase through the increase in income. So, income effect is compensated and only substitution effect is left where as in Marshallian system income is constant while the utility level might be change. (Pedersen,1998). Therefore compensated price elasticity captures only substitution effect while uncompensated price elasticity captures both price effect as well as income effect. Based on Slutsky equation, compensated and uncompensated elasticity will be similar when the share of income devoted is small and the income elasticity of $\mathrm{x}$ is small. Here compensated and uncompensated price elasticity of demand for different non-vegetarian items was found to be equal in Delhi and NCR. Uncompensated and compensated price elasticity of different non vegetarian food items in Delhi and NCR is shown in table: 4. The compensated and uncompensated price elasticity is almost equal for different non-vegetarian items in Delhi and NCR. Compensated own price elasticities of fish is -0.99 (near to -1), which means fish is almost unitary elastic in Delhi and NCR. Compensated own price elasticity is -0.39 for mutton, 6 for pork, -0.74 for chicken, -2.32 for egg and -1.31 for beef. This implies that chicken and mutton have inelastic demand while pork, egg and beef have elastic demand in Delhi and NCR. The positive sign of compensated cross price elasticities indicates a substitution relationship among different non vegetarian items whereas negative sign indicates a complimentary relationship among these items. Cross price elasticity of demand for fish with mutton was -0.36, which indicated that relationship between fish and mutton was complimentary but very weak. Cross price elasticity for fish with respect to pork, poultry, egg and beef is $-0.06,0.02,0.43$ and 0.04 respectively. This indicated that pork is very weak complementary item of fish whereas poultry, egg and beef were weak substitutes of fish for the population of Delhi and NCR.

Table 5. Uncompensated and compensated price elasticity of demand for different food items in Delhi and NCR

\begin{tabular}{|c|c|c|c|c|c|c|}
\hline \multicolumn{7}{|c|}{ Uncompensated Price elasticity } \\
\hline Food items & UP1 & UP2 & UP3 & UP4 & UP5 & UP6 \\
\hline Fish & -0.99 & -0.36 & -0.06 & 0.02 & 0.43 & 0.04 \\
\hline Goat & -0.11 & -0.39 & -0.2 & -0.72 & 0.46 & -0.01 \\
\hline Pork & -0.32 & -4.46 & -6 & 6.48 & 5.15 & 0.03 \\
\hline Poultry & 0 & -0.33 & 0.1 & -0.74 & 0.04 & -0.03 \\
\hline Egg & 0.14 & 0.52 & 0.27 & -0.12 & -2.32 & 0.1 \\
\hline Beef & 0.31 & 0.18 & 0.01 & -0.38 & 1.6 & -1.31 \\
\hline \multicolumn{7}{|c|}{ Compensated price elasticity } \\
\hline Food items & CP1 & $\mathrm{CP} 2$ & CP3 & $\mathrm{CP} 4$ & CP5 & CP6 \\
\hline Fish & -0.99 & -0.36 & -0.06 & 0.02 & 0.43 & 0.04 \\
\hline Goat & -0.1 & -0.38 & -0.2 & -0.72 & 0.46 & -0.01 \\
\hline Pork & -0.32 & -4.46 & -6 & 6.48 & 5.15 & 0.03 \\
\hline Poultry & 0 & -0.32 & 0.11 & -0.74 & 0.04 & -0.02 \\
\hline Egg & 0.14 & 0.52 & 0.27 & -0.12 & -2.32 & 0.1 \\
\hline Beef & 0.31 & 0.18 & 0.01 & -0.38 & 1.6 & -1.31 \\
\hline
\end{tabular}

Source: Estimated values/NSSO data, 2011. 


\section{Demand projections}

Aquaculture and marine sector in India is technology driven. Therefore, total factor productivity plays an important role in fish production and consumption. In this study growth in price of fish in Delhi and NCR were taken to be 4.3, growth in income as 8.8 and population growth of Delhi and NCR taken to be 3.26 (ADB, 2010). Price elasticity of demand and income elasticity of demand is estimated to be -0.98 and 0.41 respectively. With the use of given data fish demand is projected from 2011 to 2020. It is found that the fish demand in 2020 will be about $5.25 \mathrm{~kg} /$ capita/annum with a percentage increment of about $30 \%$ from $4.04 \mathrm{~kg} /$ capita/annum in 2011.

Table 6. Demand projections for fish

\begin{tabular}{|c|c|}
\hline Year & Demand in kg/capita/annum \\
\hline 2011 & 4.04 \\
\hline 2012 & 4.15 \\
\hline 2013 & 4.25 \\
\hline 2014 & 4.37 \\
\hline 2015 & 4.49 \\
\hline 2016 & 4.60 \\
\hline 2017 & 4.72 \\
\hline 2018 & 4.85 \\
\hline 2019 & 4.98 \\
\hline 2020 & 5.11 \\
\hline
\end{tabular}

Source: Estimated from results of analysis/ NSSO data, 2011.

\section{Conclusion}

Consumption (C) is the function of income (Y). As income of people increases their consumption expenditure on food and non-food also increases. Beside income, population growth and shift of dietary pattern have also a significant effect on consumption. For a fast-growing nation like India, people are shifting towards wholesome and nutritious food. They are becoming more aware about their health. So, demand for food of animal origin is increasing at very fast rate. Fish is a good example of nutritious food of animal origin. Fish is very good source of protein as well as vitamins. So, it is expected that demand for fish will increase in feature, as Indian economy is growing at a fast clip.

Per capita consumption of fish in the study region was estimated to be $4.04 \mathrm{~kg}$ / annum in 2011 , which is lower than country's per capita consumption. Fish was found to be preferred commodity among non-vegetarian items in Delhi and NCR because the share of the fish was more in the basket of all non-vegetarian items.

Income elasticity of demand for fish in Delhi and NCR is found to be 0.32, which meant fish remained a normal good. The income elasticity of other non-vegetarian items was found to be positive but less than 1. Income elasticity of fish is decreased for lower income groups to higher income groups.

Uncompensated own price elasticity of fish in Delhi and NCR was found to be -0.99 , which indicated that fish was almost unitary elastic. Uncompensated own price of other non-vegetarian items was found to be more elastic except mutton and chicken. Uncompensated cross price elasticity of fish with respect to other nonvegetarian items was found to be positive for chicken, egg and beef, which indicated that chicken, beef and eggs were substitute goods whereas the uncompensated cross price elasticity of fish with respect to mutton and pork was found to be negative, which implied that mutton and pork were complementary to fish.

Demand for fish projected up to 2020 was estimated and the demand for fish in Delhi and NCR would reach to $5.11 \mathrm{~kg} / \mathrm{capita} /$ annum from $4.04 \mathrm{~kg} / \mathrm{capita} /$ annum in 2011 with the annual average growth of $2.64 \%$. This awaits confirmation in the next round of NSSO surveys.

Funding: self-funded. 
Author contribution: conceptualization, M. Krishnan, Swadesh Prakash and Ravi Shankar Kumar; data curation, Ravi Shankar Kumar, Praduman Kumar; formal analysis, Ravi Shankar Kumar, Praduman Kumar; funding acquisition, Ravi Shankar Kumar, Swadesh Prakash; investigation, Ravi Shankar Kumar, Praduman Kumar and Dhandi Kranthi Kumar; methodology, Ravi Shankar Kumar, Praduman Kumar and M. Krishnan; project administration; Swadesh Prakash, M. Krishnan and Ravi Shankar Kumar, Badri Narayanan G.; resources, Swadesh Prakash, M. Krishnan and Ravi Shankar Kumar, Badri Narayanan G.; software, Swadesh Prakash, M. Krishnan and Ravi Shankar Kumar, Badri Narayanan G.; supervision, M. Krishnan, Praduman Kumar and Swadesh Prakash; validation, M. Krishnan, Praduman Kumar and Swadesh Prakash; visualization, M. Krishnan, Praduman Kumar and Swadesh Prakash; writing - original draft, M. Krishnan, Ravi Shankar Kumar and Praduman Kumar; writing review \& editing, Badri Narayanan G., M. Krishnan and Ravi Shankar Kumar.

\section{References}

1. Asche, F., \& Wessells, C. R. (1997). On price indices in the almost ideal demand system. American Journal of Agricultural Economics, 79(4), 1182-1185. [GoogleScholar].

2. Blundell, R., Pashardes, P., \& Weber, G. (1993). What do we learn about consumer demand patterns from micro data?. The American Economic Review, 570-597. [GoogleScholar].

3. Deaton, A., \& Muellbauer, J. (1980). An almost ideal demand system. The American economic review. 70(3), 312-326. [GoogleScholar].

4. Dey, M. M. (2000). Analysis of demand for fish in Bangladesh. Aquaculture Economics \& Management. 4(1-2), 63-81. [GoogleScholar].

5. Eales, J., \& Wessells, C. R. (1999). Testing separability of Japanese demand for meat and fish within differential demand systems. Journal of Agricultural and Resource Economics, 114-126. [GoogleScholar].

6. FAO, F. (2014). Aquaculture Department, The State of World Fisheries and Aquaculture. [Link].

7. Fan, S., Wailes, E. J., \& Cramer, G. L. (1995). Household demand in rural China: a two-stage LESAIDS model. American Journal of Agricultural Economics. 77(1), 54-62. [GoogleScholar].

8. Garcia, Y. T., Mohan Dey, M., \& Navarez, S. M. M. (2005). Demand for fish in the Philippines: A disaggregated analysis. Aquaculture economics \& management, 9(1-2), 141-168. [GoogleScholar].

9. Heien, D., \& Wesseils, C. R. (1990). Demand systems estimation with microdata: a censored regression approach. Journal of Business \& Economic Statistics, 8(3), 365-371. [GoogleScholar].

10. Hicks, J.R. (1969). A Revision of Demand Theory, Oxford University Press, 1956. First Edition. [Link].

11. Hicks, J.R. (1985). Method of Dynamic Economics, Clarendon Press. [Link].

12. Kumar, P., \& Dey, M. M. (2004). A study on modelling of household demand for fish in India. Indian Journal of Agricultural Economics, 59(3), 465. [Link].

13. Kumar, P., Dey, M. M., \& Paraguas, F. J. (2005). Demand for fish by species in India: Three-stage budgeting framework. Agricultural Economics Research Review, 18(2), 167-186. [GoogleScholar].

14. Kumar, R. S., Kumar, P., Krishnan, M., Vinay, A., \& Kumar, D. K. (2017). Consumption Pattern of Fish in Uttar Pradesh, India. Int. J. Curr. Microbiol. App. Sci, 6(9), 2854-2861. [GoogleScholar].

15. Kumar Ravi Shankar (2016). Estimation of demand for fish in Delhi and NCR, unpublished master of science (Fisheries Economics) dissertation, Fisheries Economics, Extension and Statics division, ICAR-Central Institute of Fisheries Education, Mumbai 400061, India. [Link].

16. Moschini, G. (1995). Units of measurement and the Stone index in demand system estimation. American Journal of Agricultural Economics, 77(1), 63-68. [GoogleScholar].

17. Marshall Alfred (1890). Principles of Economics, MacMillan, London. [Link].

18. Marshall Alfred (1892). Elements of Economics, Oxford University Press. [Link].

19. NSS, $68^{\text {th }}$ round (2011). Household consumption of various goods and services in India. [Link].

20. Pederson, Eric \& Danziger, Eve \& Wilkins, David \& Levinson, Stephen \& Kita, Sotaro \& Senft, Gunter. (1998). Semantic Typology and Spatial Conceptualization Author(s). Language. 74. 10.2307/417793. [GoogleScholar].

21. Tiffin, A., \& Tiffin, R. (1999). Estimates of food demand elasticities for Great Britain: 19721994. Journal of Agricultural Economics, 50(1), 140-147. [GoogleScholar]. 